\title{
Economic Growth Decoupling Municipal Solid Waste Loads in Terms of Environmental Kuznets Curve: Symptom of the Decoupling in India
}

\author{
Anupam Khajuria \\ Research Fellow, Division of Sustainable Energy and Environmental Engineering \\ Graduate School of Engineering, Osaka University, Osaka \\ Yamadaoka 2-1, Suita, Osaka 565-0871, Japan \\ Takanori Matsui \\ Assistant Professor, Division of Sustainable Energy and Environmental Engineering \\ Graduate School of Engineering, Osaka University, Osaka \\ Yamadaoka 2-1, Suita, Osaka 565-0871, Japan
}

Takashi Machimura

Associate Professor, Division of Sustainable Energy and Environmental Engineering

Graduate School of Engineering, Osaka University, Osaka

Yamadaoka 2-1, Suita, Osaka 565-0871, Japan

Received: February 16, 2011

Accepted: March 2, 2011

doi:10.5539/jsd.v4n3p51

\begin{abstract}
This paper provides a specific application of the Environmental Kuznets curve is a hypothetical relationship between various indicators of environmental degradation and income per capita. In the early stages of economic growth degradation and pollution increases, but beyond some level of income per capita it tends to reverse, so that at high economic growth leads to environmental improvement. This implies that the environmental impact indicator is an inverted U-shape with income per capita. With respect of the income, hypothetical turning point would eventually occur with the characteristic of Environmental Kuznets Curve (EKC). India also serves kinds of improvement or opportunities that could be pursued in other developing countries. The main purpose is contributing to enhance the connection decoupling between economic growth and municipal solid waste generation in developing countries such as India, in which relevant data are more readily available. India is an interesting subject of study because of its large territory, rapid economic growth and differentiated regions. In the first phase, this article analyzes the course of GDP per capita with municipal solid waste generation from 1947 to onwards to 2004. In this article in the second phase, regression analysis among the municipal solid waste management factors is conducted on state wide data set in order to find the key stage for efficient environmental improvement. In the final phase, aiming to promote the decoupling between the comparison of environment performance among the state-wide data set.
\end{abstract}

Keywords: Municipal solid waste, Economic growth, Environmental Kuznets Curve (EKC), Decoupling, Sustainable development

\section{Introduction}

The key to dealing with different stages of economic development is the environmental Kuznets curve (EKC), the hypothesis that pollution increases at first during development and then declines after industrialization in an inverted U-shaped pattern of pollution emissions against time (Acheson, 1988). This term derives from the earlier empirical observation of a tendency for income to first become more unequal and then more equal as societies move through the industrialization process (Kuznets, 1955), producing a similar inverted U-shape when time is on the horizontal axis and the Hasuman (which rises with income inequality) is on the vertical axis. These both suggest that societies may bear temporary costs to develop. However, critics have argued that they 
may not generally hold, being subject to historical, institutional, geographic, and technological specificities (Abrate and Ferraris, 2010).

Discussion during the recent years on the dissociation of the positive relationship between economic growth and resource utilization is called Environmental Kuznets Curve (EKC) (Kuznets, 1955). EKC is a hypothesis that states the resource utilization or pollution initially increases with the per capita income and then eventually declines because the willingness to pay for environmental quality increases with income and this characteristic form an inverted U-shaped relationship between pollution emission and affluence (Dinda, 2004) (Figure 1). Research works on linking of EKC to materials and municipal waste are less as compared to air pollution and GHG emission. As noted (Kaurosakis, 2006) most evidences on the determinants of municipal waste generation (collection) are based on US microeconomic studies carried out at the local community level. Wang et al 1998 also found evidence in favor of a negative elasticity by focusing on US stocks of hazardous waste as an environmental impact indicator and by using a country-based cross sectional data set.

\section{<insert Figure 1 here>}

No relationship between EKC and municipal solid waste was found in Europe (Mazzanti and Zoboli, 2005). Mazzanti, 2007 stated "de-linking relation between Economic, Municipal solid waste and Environment" and also noted that "it has been shown to apply to a selected set of pollutants only," but some economists "have conjectured that the curve applies to environmental quality generally". Empirical evidences on de-linking related to environmental waste indicators are very scarce. No turning point in EKC was found with environmental indicators with respect of per capita municipal waste, which monotonically increase with income from the period of 1975-1990 in 13 OECD countries (Cole et al., 1997).

In contrast, increased level of municipal solid waste may pose the significant threats to environmental quality and human health. Economic conditions may have a very important role in determining the emergence of the downward sloping part of the EKC (Kuznets, 1995). The EKC is a story about how a country's pollution will change as that country's economy grows. The income of a country may be significant in determining the 'zeal and effectiveness' of its pollution regulatory structure because a richer state is likely to have more resources available to regulatory agencies, higher public preferences for improved environmental quality and a greater perceived danger from environmental factor (Torras \& Boyce, 1998).

India is an interesting subject of study because of its large territory, rapid economic growth and differentiated regions. This article conducted the regression analysis among the municipal solid waste management factors is conducted on state wide data set in order to find the key stage for efficient environmental improvement.

\section{Data Source and Methodology}

The changes in the mechanism of urban growth described EKC model can be seen as imparting of huge impact on urban environmental issue. The production of waste is the more relevant environmental pressure indicator: more waste means more disposals loads, more management costs, and more environmental externalities.

\section{$<$ insert Figure 2 here $>$}

I used the data of 17 Indian States (Figure 2) with 6 variables (i.e. Net State domestic product (in Rupee INR Crore), Municipal solid waste generation (ton per capita per year), Geographic area(sq. km), Biological Oxygen Demand (mg/l), Chemical Oxygen Demand (mg/l) and Literacy rate (\%age) ) as; demographic and economic factors and literacy rate, municipal solid waste generation in 2001(India Stat, 2010) (Appendix A). Therefore in this article, the linkage concerning impacts and correlation among the factors was analyzed by regression analysis. Regression analysis is a statistical tool for the investigation of relationships between variables. Usually, the analysis seeks to ascertain the causal effect of one variable upon another-the effect of a price increase upon demand, for example, or the effect of changes in the money supply upon the inflation rate.

\section{Results}

The EKC refers to the relationship between environmental indicators of certain types and per capita incomes of countries; its origins lie in Kuznets work in the 1950's on income inequality measures across developing countries. The EKC hypothesis is that environmental indicator levels first rise (pollutant levels per capita rise) as per capita income rises; then the relationship reverses after some threshold level of income is called "Turning point". World Bank (2002) examined a range of environmental indicators. These included lack of clean water, lack of urban sanitation, ambient levels of suspended particulate matter, ambient sulfur oxides, and change in forest area. 
Correlation between factors corresponding of municipal solid waste management was analyzed using a state wide dataset. In Figure 3, the relationship between net states domestic product and annual amount of municipal solid waste is shown. The high correlation coefficient $\left(\mathrm{r}^{2}=0.78\right)$ shows a strong relation between net state domestic product and municipal solid waste generation, and it implies no decoupling between them. Studied on the energy, productivity and economic growth correspond to set of empirical studies including studies on economic history (Richmond and Kaufman, 2006). There is no causal evidence found in the energy conservation policies, GDP per capita and carbon dioxide emission (Acaravic and Ozturk, 2010; Ozturk and Acaravic, 2010)

\section{<insert Figure 3 here>}

The present correlation analysis of seventeen states of India showed that the higher net state domestic product leads to the high amount of municipal solid waste in general, whereas there are a few unique states. Andhra Pradesh (AP) showing the highest total municipal solid waste generation per year and a moderate high net state domestic production experiences on going rapid industrial development and urbanization. Hyderabad city, the capital of Andhra Pradesh State holds more than 300 industrial estates (NEERI, 1989) of mainly chemical and pharmaceutical, and some heavy metal industries. The lowest total municipal solid waste generation is shown in Chandigarh State $(\mathrm{C})$ because it is the Union territory and urbanization occurs as moving to the sustainable society promoted by the government. In the other states of India like Assam (A), Delhi (D), Gujarat(G), Himachal Pradesh (HP), Karnataka (KAR), Kerala (K), Madhya Pradesh (MP), Manipur (MAN), Meghalaya (MEG), Orissa (O), Punjab (PUN), Tamil Nadu (TN) is showing the increasing order of waste generation corresponding the increasing order of urbanization and industrialization.

\section{<insert Figure 4 here>}

Above analysis was based on state total economy and state total amount of waste. Next analysis compared activity intensities in economy and waste generation. In Figure 4, the relationship between net state domestic product per capita and annual municipal solid waste generation per capita is shown. Municipal solid waste generation had weak positive correlation with net domestic product per capita for entire range, but showed different properties in the lower and higher product range. Most states positioned under 30 thousand Rs. of net domestic product per capita and the waste generation per capita of them significantly correlated with net domestic product per capita. Whereas for the higher product states, waste generation per capita was almost similar or was slightly decreasing with increasing net domestic product per capita. Therefore, per capita municipal solid waste generation showed decoupling with per capita net domestic product in the higher product states. Again, robustness of this EKC-like shape would depend on a few samples in the higher economic product states; however reliability of the used dataset in this analysis should be higher than the previous one because the same governmental organization conducted measurement in all states in the equal methodology.

Positions of some states in the per capita measure (Figure 4) were different from those in the state total measure (Figure 5). For example, Chandigarh State (C), having the lowest total waste generation, actually showed a middle higher waste generation per capita, and more extremely, it showed the highest economic product per capita although it belonged in the bottom states of total net domestic product. Another important measure is environmental performance of the states. There exists a considerable gap in per capita waste generation among states having similar net domestic product per capita. For example, waste generation per capita of Andhra Pradesh State (AP) is more than twice of Kerala State (K) indicating a worse environmental performance. Comparison among states having different performance can provide valuable knowledge for improvement, and this aspect will be discussed in the other variables.

\section{Response to attain the decoupling}

In previous sections, inter-linkages among the factors of municipal solid waste management were investigated. Economic development was found to link strongly to municipal solid waste generation, whereas a sign of decoupling between economy and environment has been detected in the states with high net domestic product per capita. Now defines the response aiming to promote the decoupling between the comparisons of environmental performance among the states.

The environmental performance of a state in waste management can be measured by waste generation and economic standard. We propose the eco-efficiency is not limited simply to making incremental efficiency improvements in existing practices and habits. On the contrary, eco-efficiency should stimulate creativity and innovation in the search for new ways of doing things as an index "eco-efficiency" as net state domestic product per municipal solid waste generation. Eco-efficiency of 17 Indian states is shown in Figure 5. The best eco-efficiency in India was in Chandigarh State (C) showing 0.40 million Rs per ton followed by Manipur (MAN) and Kerala (K) States, whereas the worst was in Madhya Pradesh State (MP) showing 0.08 million Rs 
per ton followed by Andhra Pradesh (AP) and Orissa (O) States. Chandigarh State, as already mentioned, is a small and highly urbanized state where sustainability is promoted by the government. Manipur and Kerala States are moderately urbanized but population density is quite different; low in Manipur and quite high in Kerala. Net state domestic production per capita is high in Chandigarh, middle in Kerala and low in Manipur. Thus, there are no common demographic, geographic and economic properties among the highest eco-efficiency states. Alike, no common properties are found among the lowest eco-efficiency states; Madhya Pradesh, Andhra Pradesh and Orissa.

\section{<insert Figure 5 here $>$}

There is a very probable factor that defines eco-efficiency. Figure 6 shows relationship between literacy rate and eco-efficiency of 17 Indian states. Literacy can explain $46 \%$ of variation in eco-efficiency. The highest literacy rate was $90.86 \%$ in Kerala State $(\mathrm{K})$ of which eco-efficiency was the third highest. The fact literacy rate was positively correlated with net state domestic product per capita but not correlated with municipal solid waste generation per capita suggests that education would promote decoupling between economic growth and environmental burden.

\section{<insert Figure 6 here $>$}

I discussed the eco-efficiency of Kitakyushu (KY), Japan as a reference of developed country. Economic measure of Kitakyushu was converted into the same unit of Indian states by currency exchange rate. Kitakyushu has a population comparative to Chandigarh State (C) but generates twice larger municipal solid waste per capita. Domestic product per capita of Kitakyushu was 25 times larger than Chandigarh making 10 times larger eco-efficiency. Literacy rate of Kitakyushu is $100 \%$. By predicting from the regression line in Figure 6, the maximum eco-efficiency that Indian states can attain by achieving $100 \%$ literacy rate is 0.38 million Rs per ton, and there still exists a big efficiency gap with developed countries. This may be the limit of domestic policies in developing countries to raise eco-efficiency.

Kitakyushu is one of the advanced model cities that promote the Reuse, Reduce and Recycle (3Rs) initiative both in municipal and industry sectors. Matsumoto et al. 2007 found that, in the absence of a comprehensive recycling policy for individual products and appropriate technology development, it is extremely difficult to improve recycling levels for end of life products. Another gap with developed counties is infrastructure as 'though waste management infrastructure has improved in recent years there are considerable infrastructure deficits, including large-scale and local facilities'. To narrow the policy and infrastructure gap on the way of economic growth, transfer of advanced knowledge in developed countries is indispensable.

\section{Conclusions}

The present environmental Kuznets curve should be viewed as the hypothesis on the interaction between economic growth and environmental quality. The evidence suggests that there is an aggregate relationship between specific environmental pollutants such as municipal solid waste generation and income per capita, however, the shape of the relationship is not uniform across pollutants and turning points, when they exist, differ across pollutants.

In an optimistic view, the process of globalization may render the world's development more sustainable simply by pushing the world economy towards the decreasing part of the bell-shaped Environmental Kuznets Curve. However, progress of research still needs to be made in order to learn which variables do have a turning point in their relation with output so that we can decide which policies to follow. A practical application was conducted in to investigate relationship between among the factors of municipal solid waste management, and to find possible response to attain the decoupling through analysis of Indian states. A sign of decoupling between economic and waste generation rate as was also found in a few economically advanced states. Eco-efficiency was defined as an indicator of decoupling progress, and it was found that literacy rate significantly determines the eco-efficiency of Indian states. This suggests importance of education as domestic policy to improve waste management; however its limit was also shown by comparison with a developed country.

\section{References}

Abrate, G and Ferraris, M. (2010). The Environmental Kuznets Curve in the Municipal solid waste sector. Working paper no. 1, Hermes, Fondazione Collegio Carlo Alberto, Torino, Italia.

Acaravci, A., Ozturk, I. (2010). On the Relationship between Energy Consumption, CO2 Emissions and Economic Growth in Europe. Energy, 35(12), 5412-5420.

Acheson James M. (1988). The Lobster Gangs of Maine. Hanover: University Press of New England. 
Cole, M.A., Rayner, A.J. \& Bates, J.M. (1997). The environmental kuznets curve: an empirical analysis. Environment and Development Economics, 2(4), 401-416.

Dinda, S. (2004). Environmental Kuznets curve hypothesis: a survey. Ecological Economics, 49, 431-55.

India stat. (2010). http://www.indiastat.com> (reffered 05.07.2010).

Kaurosakis, K. (2006). MSW generation, disposal and recycling: a note on OECD inter-country differences. Applied Environmental Economics Conference, $24^{\text {th }}$ March, The Royal Society, London

Kuznets S. (1955). Economic growth and income inequality. American Economic Review 45:1-28.

Kuznets, S. (1995). Economic growth and income inequality. American Economic Review, 45,1-28.

Matsumoto, T., Liu, J., Koyanagi, H. \& Ogihara, A. (2007). Present situation and issue on construction of venous industrial parks in China: implication from international comparison between Qingdao and Kitakyushu, Proceeding of $35^{\text {th }}$ Annual Meeting of Environmental Systems Research, 135-141.

Mazzanti, M. \& Zoboli, R. (2005). Delinking and environmental kuznets curves for waste indicators in Europe. Environmental Science, 2, 409-425.

Mazzanti, M. (2007). Is waste generation delinking from economic growth?. Applied Economics letters, 15, 287-291.

National Environmental Engineering Research (NEERI). (1989). Report on Patancheru Industrial Area, India, 185.

Online map. (2010). <http://www.http://www.funmin/online/indiamap/index/php> $\quad$ (reffered 20.08.2010).

Ozturk, I., Acaravci, A. (2010). CO2 Emissions, Energy Consumption and Economic Growth in Turkey. Renewable and Sustainable Energy Reviews, 14, 3220-3225.

Richmond, AK, \& Kaufman, RK. (2006). Is there a turning point in the relationship between income and energy use and/or carbon emissions? Ecological Economics, 56, 176-89.

Torras, M. \& Boyce, J.K. (1998). Income, inequality and pollution: a reassessment of the environmental kuznets curve. Ecological Economics, 25, 147-160.

Wang, P., Bohara, A., Berrens, R. \& Gawande, K. (1998). A risk based environmental Kuznets curve for US hazardous waste sites. Applied Economics Letters, 5, 761-763.

World Bank. (2002). 1.1 Size of the Economy. http:// www.worldbank.org /data/ wdi2001/pdfs/ tab1_1. pdf. (accessed on 18th October 2004)

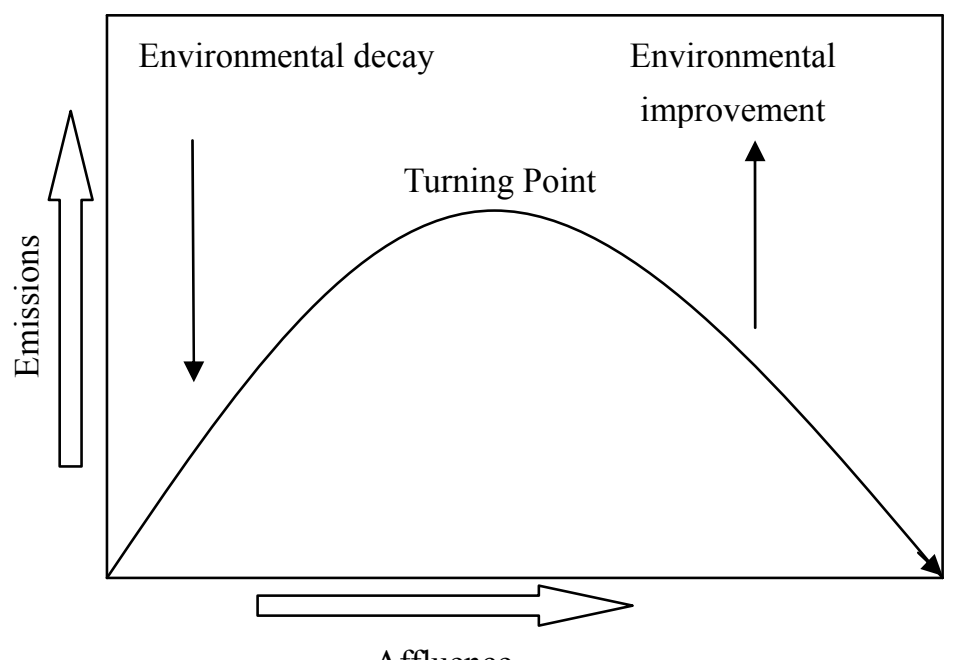

Affluence

Figure 1. The Environmental Kuznets Curve (EKC)

Source: (Kuznets 1995) 


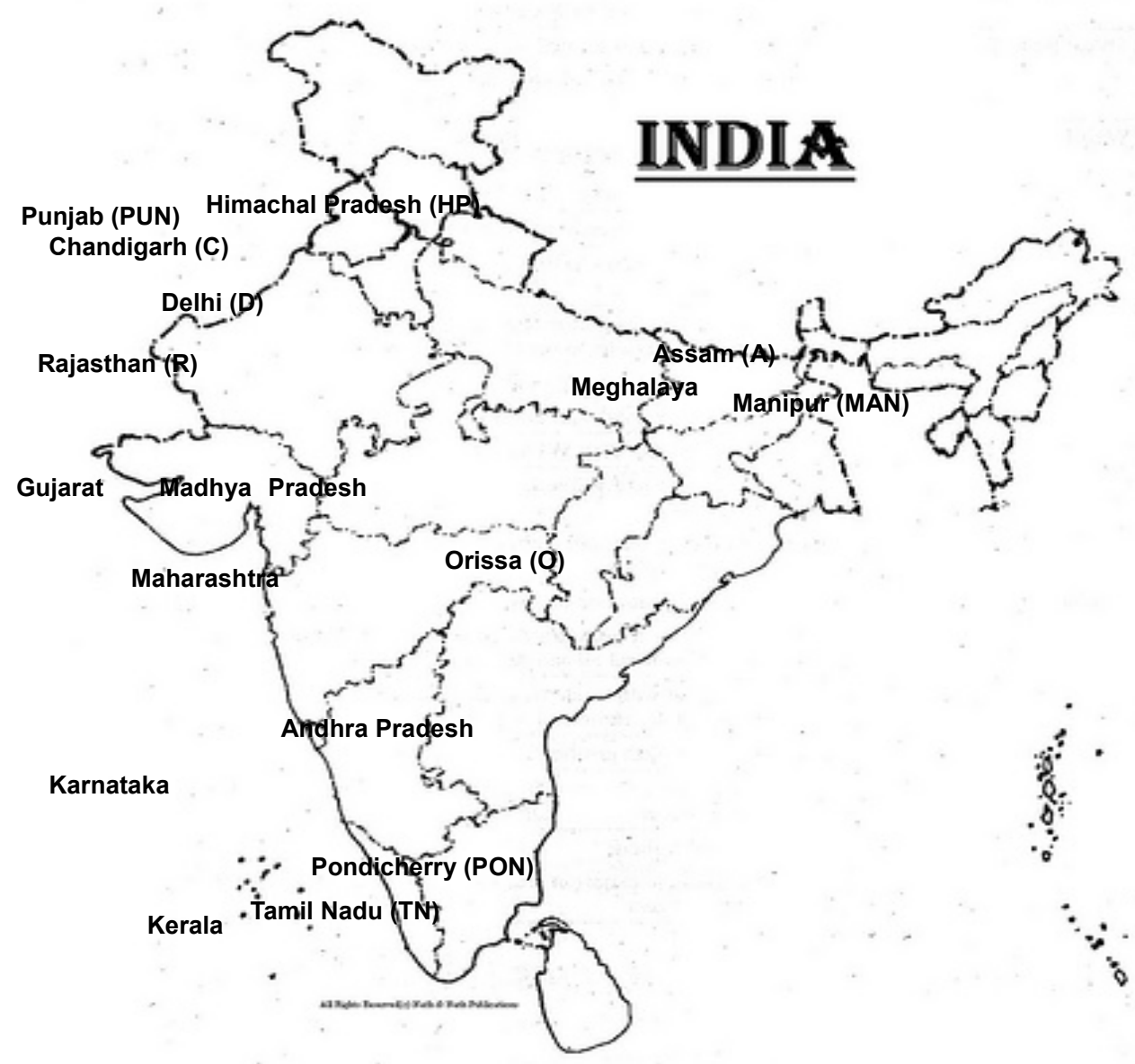

Figure 2. Selected 17 States of India for analysis in Phase II

Source: (Online map 2010)

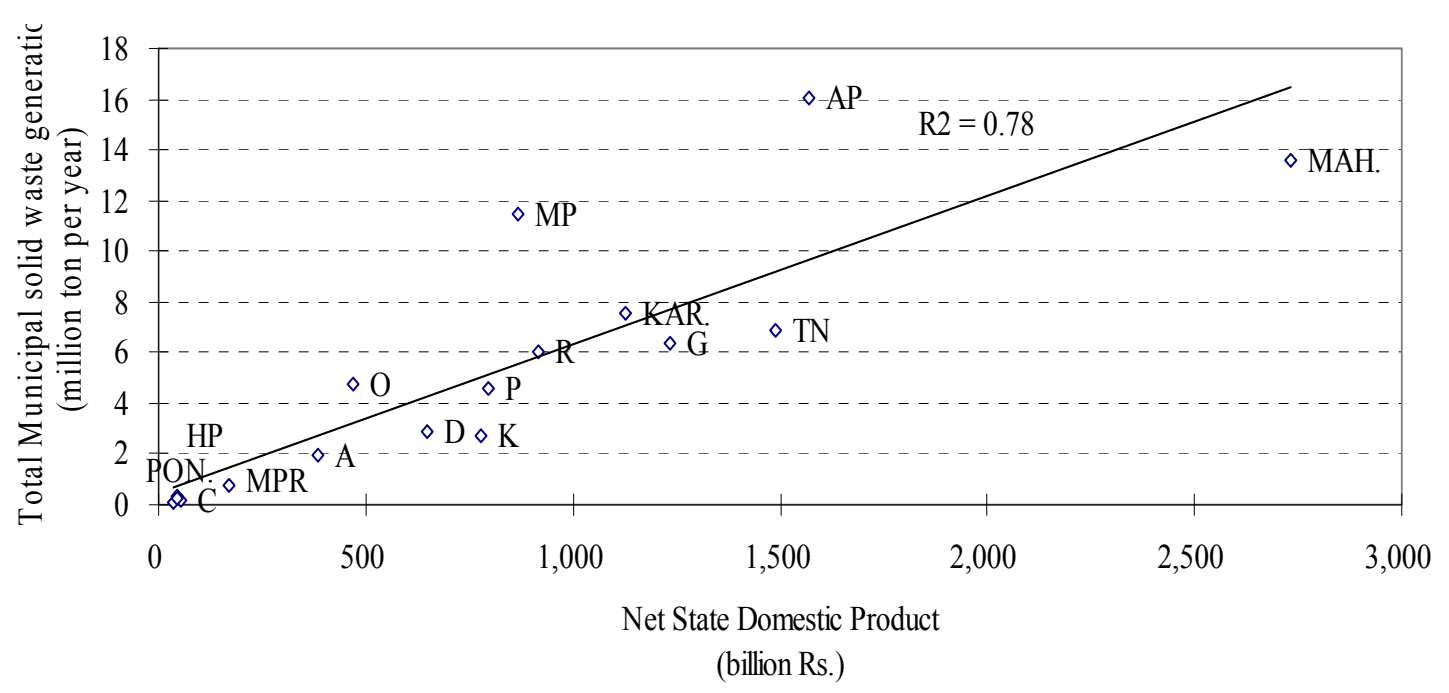

Figure 3. Relationship of Net State Domestic Product and the amount of municipal solid waste generation 


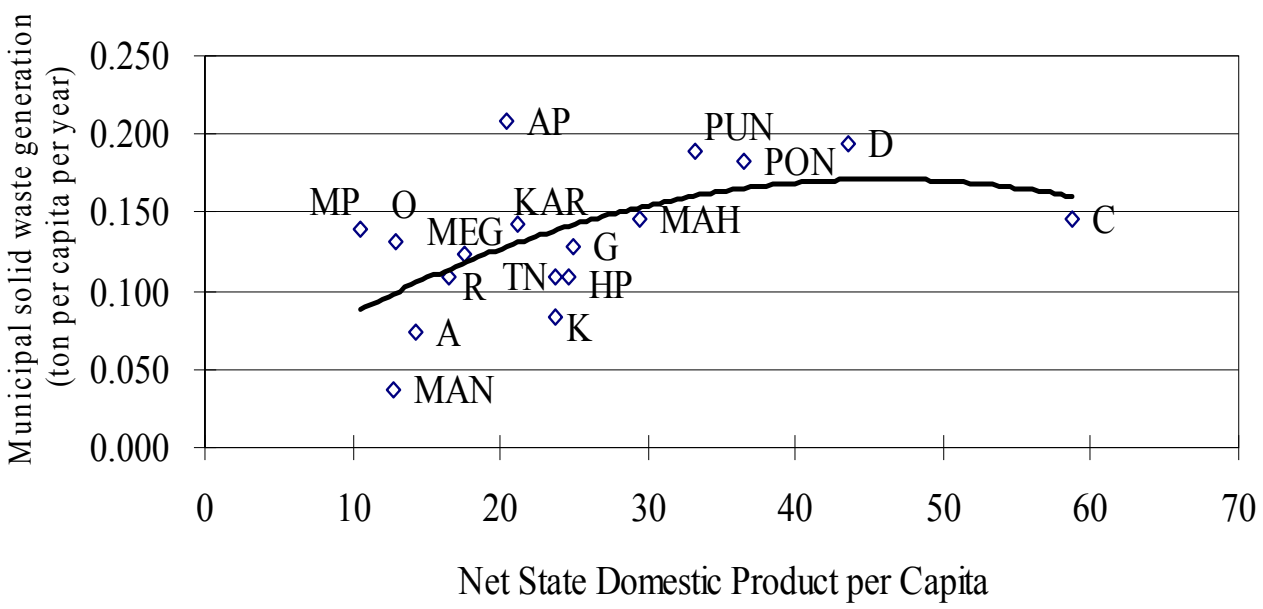

Figure 4. Relationship between Net State Domestic Product per capita and municipal solid waste generation per capita

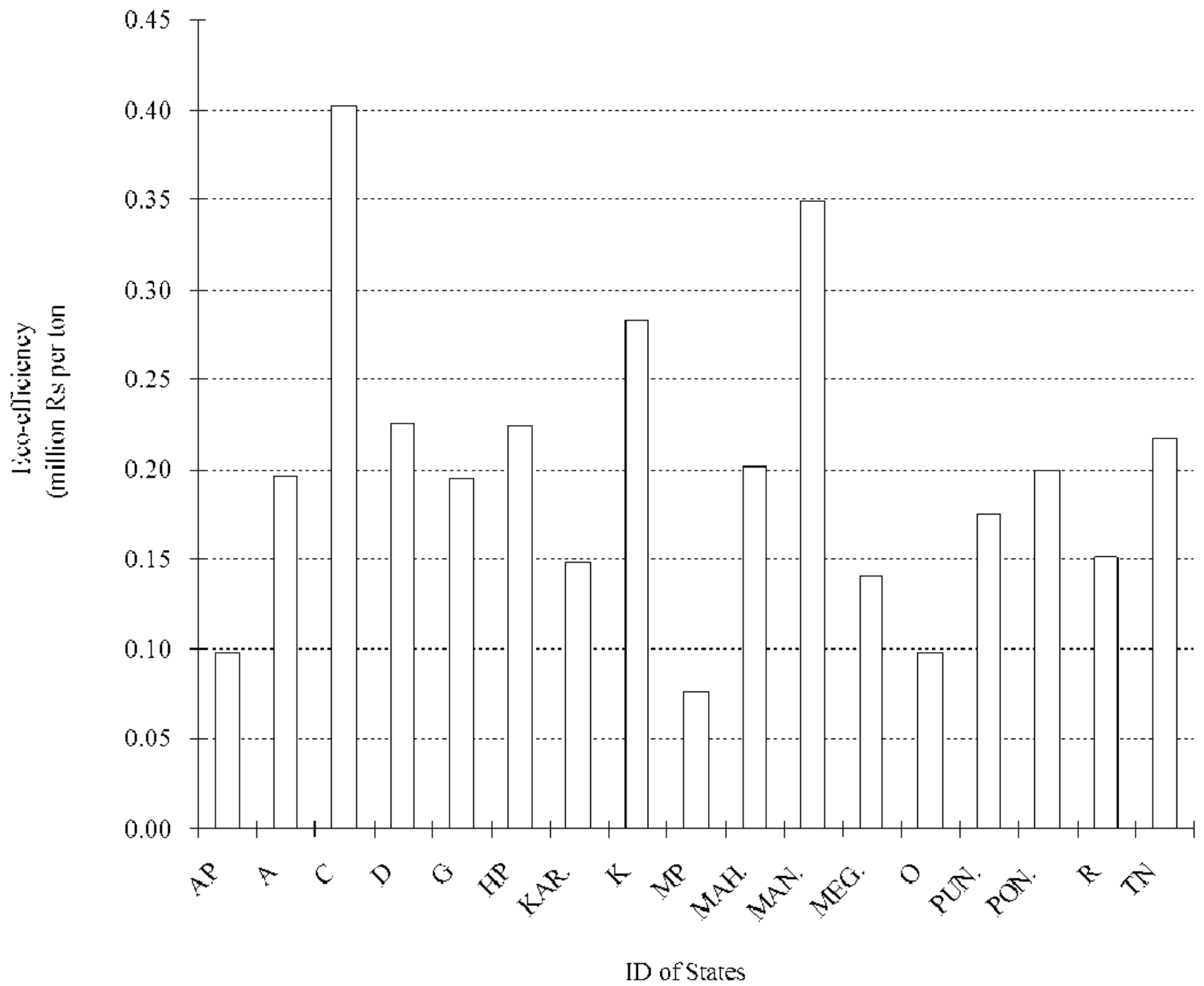

Figure 5. Eco-efficiency of 17 Indian states 


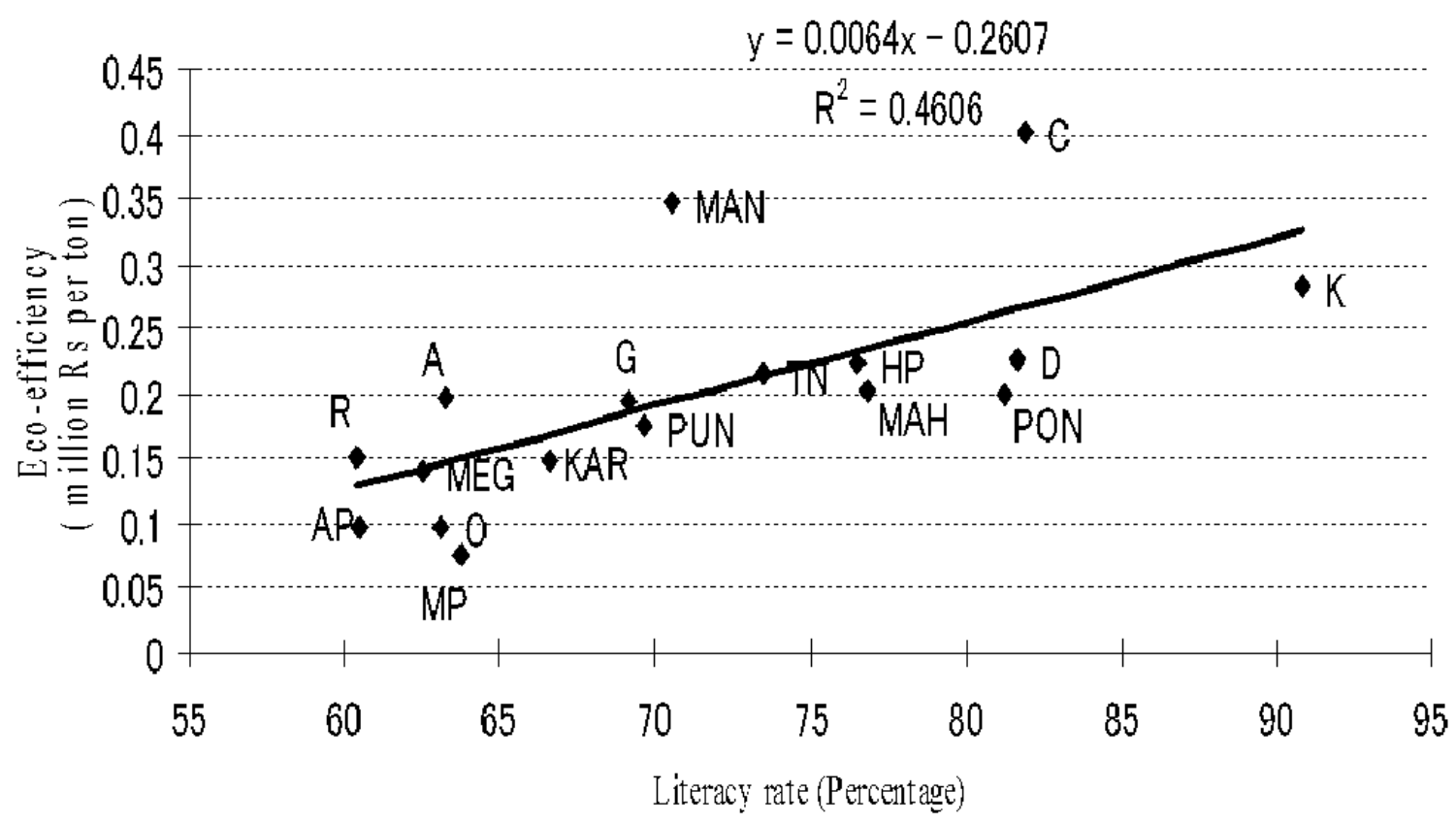

Figure 6. Relationship between literacy rate and eco-efficiency of 17 Indian states

\section{Appendix A}

Factors of the municipal solid waste management of selected 17 States in India in 2001.

\begin{tabular}{|c|c|c|c|c|c|c|}
\hline State name & $\begin{array}{l}\text { Net State } \\
\text { domestic } \\
\text { product } \\
\text { (in Rupee } \\
\text { INR } \\
\text { Crore) }\end{array}$ & $\begin{array}{l}\text { Municipal } \\
\text { solid waste } \\
\text { generation } \\
\text { (ton per } \\
\text { capita per } \\
\text { year) }\end{array}$ & $\begin{array}{l}\text { Geographic } \\
\text { area(sq. } \\
\text { km) }\end{array}$ & $\begin{array}{l}\text { Biological } \\
\text { Oxygen } \\
\text { Demand } \\
(\mathrm{mg} / \mathrm{l})\end{array}$ & $\begin{array}{l}\text { Chemical } \\
\text { Oxygen } \\
\text { Demand } \\
(\mathrm{mg} / \mathrm{l})\end{array}$ & $\begin{array}{l}\text { Literacy } \\
\text { rate } \\
\text { (\%age) }\end{array}$ \\
\hline Andhra Pradesh (AP) & 157,150 & 0.208 & 275,045 & 6.500 & 39.520 & 60.47 \\
\hline Assam (A) & 38,313 & 0.073 & 78,438 & 4.100 & & 63.25 \\
\hline Chandigarh (C) & 5,490 & 0.146 & 13,256 & & & 81.94 \\
\hline Delhi (D) & 65,027 & 0.193 & 16,152 & 16.000 & 56.500 & 81.67 \\
\hline Gujarat (G) & 123,573 & 0.128 & 196,024 & & & 69.14 \\
\hline Himachal Pradesh (HP) & 17,148 & 0.110 & 55,673 & & & 76.48 \\
\hline Karnataka (KAR) & 112,847 & 0.142 & 191,791 & & & 66.64 \\
\hline Kerala (K) & 77,924 & 0.084 & 38,863 & & & 90.86 \\
\hline Madhya Pradesh (MP) & 86,745 & 0.139 & 308,245 & & & 63.74 \\
\hline Maharashtra (MAH) & 273,188 & 0.146 & 307,713 & & & 76.88 \\
\hline Manipur (MAN) & 3,369 & 0.037 & 22,327 & & & 70.53 \\
\hline Meghalaya (MEG) & 4,478 & 0.124 & 22,429 & 1.100 & 3.200 & 62.56 \\
\hline Orissa $(\mathrm{O})$ & 46,946 & 0.131 & 155,707 & & & 63.08 \\
\hline Punjab (PUN) & 79,611 & 0.190 & 50,362 & 1.500 & 8.000 & 69.65 \\
\hline Pondicherry (PON) & 4,259 & 0.183 & 50,148 & & & 81.24 \\
\hline Rajasthan (R) & 91,771 & 0.110 & 342,239 & 16.300 & 79.000 & 60.41 \\
\hline Tamil Nadu (TN) & 148,861 & 0.110 & 130,058 & 5.400 & 56.500 & 73.45 \\
\hline
\end{tabular}

Source: (Web site of India stat 2010) 